\title{
Revisiting the famous farm foxes: A psychological perspective
}

\author{
Jonathan D. Lane ${ }^{1}$ \\ Published online: 2 July 2018 \\ (C) Psychonomic Society, Inc. 2018
}

\begin{abstract}
Five decades ago, Dmitry Belyaev, Lyudmila Trut, and colleagues began a now-famous experiment, selectively breeding foxes based on one criterion: perceived tame behavior. Over generations, the fox population changed in behavior (as predicted) but, intriguingly, also changed markedly in appearance - for example, many had wider mouths, curlier tails, different fur coloring, and floppy ears. These researchers concluded that the morphological changes that appeared in their foxes were a by-product of the researchers' selecting for genetic variants that are implicated both in behavior and in appearance. For decades, scientists have largely accepted this "shared genetic variants" interpretation to fully account for the co-occurrence of behavioral and morphological phenotypes in these foxes and in other domesticated animals. However, several decades of psychological research on human social cognition, human-canine interaction, and canine behavior strongly suggest that such an account may be incomplete. I forward a supplementary perspective, based on psychological research, that the covariation of appearance and behavior among these foxes may be partly an artifact of human psychological processes at play in selection. These processes include humans' tendency to infer individuals' traits based on their physical features; trait inferences, in turn, influence how humans treat those individuals. If accurate, this account bears on our understanding of these famous foxes, human-canine interactions, as well as humans' role in domestication.
\end{abstract}

Keywords Social cognition $\cdot$ Canines $\cdot$ Humans $\cdot$ Domestication

In 1959, Dmitry Belyaev and his research team initiated an intriguing and ambitious investigation into the domestication of wild canines (Belyaev, 1979; Trut, 1999). Belyaev suspected that the domestication of dogs (Canis familiaris) took place as humans selected canines based on one criterion - behavior; specifically, nonaggressiveness and fearlessness toward humans. Lyudmila Trut was in charge of the on-ground effort to test this hypothesis. She located a fox farm in the southern Soviet Union, near the borders of Kazakhstan and Mongolia (Dugatkin \& Trut, 2017). These foxes (Vulpes vulpes) had been bred in captivity for decades, but the foxes had "never undergone any special selection for behavior," and many of the biological characteristics of the wild species had been persevered (Belyaev, 1979, p. 301). Trut visited the farm four times a year, to assess hundreds of foxes' behavior as she approached, opened, and placed sticks inside their cages. She evaluated the tameness of each fox, and the most tame foxes (roughly $10 \%$ of the population) were separated from the rest; these

Jonathan D. Lane

jonathan.lane@vanderbilt.edu

1 Vanderbilt University, Nashville, TN, USA foxes became the core population with which a multitude of studies were conducted (Dugatkin \& Trut, 2017). For the offspring of these foxes and for each subsequent generation, researchers attempted to interact with the foxes, recorded the foxes' reactions, and allowed for only those foxes with a specific temperament profile to breed - foxes that were less aggressive and less fearful toward the researchers, and thus "similar in their behavior to the domestic dog" (Belyaev, 1979, p. 302).

After just three generations, many offspring began to exhibit temperaments that were more "dog-like"- they were less aggressive toward humans and approached humans with less fear (Trut, 1999; Trut, Plyusnina, \& Oskina, 2004). Additionally and surprisingly, starting between Generations 8 and 10 , foxes increasingly possessed more dog-like physical traits compared with their wild ancestors and compared with control populations: They were more likely to have floppy ears, curled tails, wider faces, and fur with brown or white spotting. Compared with a control population, in this "domesticated" population pigmentation anomalies (e.g., mottling, star patterns) were more than 24 times as common, curled tails were more than 10 times as common, and floppy ears were 35\% more common (although each trait was found in only a few animals per 100; Trut, 1999). The researchers 
concluded that such physical differences were "due to prolonged selection for a tame genotype" (Belyaev, 1979, p. 303). By implication, dogs came to look more "dog-like" because of how humans selected them based on their temperament.

This work stimulated new scientific interest on the correlation of seemingly unrelated phenotypes in dogs and other species (e.g., Brunberg, Gille, Mikko, Lindgren, \& Keeling, 2013; Pérez-Guisado, Lopez-Rodríguez, \& Muñoz-Serrano, 2006; Stelow, Bain, \& Kass, 2016), and put dogs at the forefront of genetics research (Kubinyi, Sasvári-Székely, \& Miklósi, 2011), including work that might contribute to understanding the genetic architecture of human personality (Jensen et al., 2016). Recently, this work inspired psychological research that has informed the theory that the tame temperaments possessed by these foxes and by typical dogs allows for their expression and learning of social-cognitive skills that are similar to some skills possessed by human toddlers (Hare, 2007; Lakatos, Soproni, Dóka, \& Miklósi, 2009; Miklósi, Topál, Hare, \& Tomasello, 2005). Subsequently, this research inspired work examining links between young children's temperaments and their social cognition, revealing that preschoolers who are less aggressive and those who are shy yet socially observant and nonreactive have a superior understanding of others' minds (Lane et al., 2013; Song, Volling, Lane, \& Wellman, 2016; Wellman, Lane, Labounty, \& Olson, 2011). Thus, Belyaev and Trut's research program has led to intriguing psychological research with humans. As well, canine research has borrowed from psychological research with humans - for example, measures of children's cognition and behavior are often adapted to gauge these qualities in canines (Kubinyi et al., 2011). Here, I continue this cross-pollination by forwarding a psychological account that adds nuance to the story of these famous foxes and potentially to the story of canine domestication. This account is based on psychological research and might help to further explain why the farm foxes changed not only in temperament but also in appearance over generations.

The reason for the foxes' increasing tameness across generations is straightforward: Belyaev and his team purposely selected foxes that were perceived as tamer, less aggressive, and less fearful. However, the link between the selection for tameness and increasing dog-like appearances is less obvious. Why should temperament and physical appearance covary? Many years before the farm-fox study, scholars had noted links between physical appearance and temperament in various species, especially among domesticated animals (Darwin, 1859; Keeler, 1947). Indeed, developmental psychologists have even identified links between temperament and craniofacial morphology in human infants (Arcus \& Kagan, 1995). But the changes found across generations for so many aspects of the farm foxes' appearance - wider snouts, lighter or mottled coats, curly tails, floppy ears—are particularly striking. ${ }^{1}$
These associations between temperament and appearance fascinated Belyaev, Trut, and others, who attempted to account for such links. Most accounts cite genetic variants that are implicated in both behavioral and physiological development (Trut, Oskina, \& Kharlamova, 2009). On these accounts, selecting for certain behaviors among the foxes effectively selected for certain genetic variants; those same variants were also implicated in physiological development, thus accounting for the co-occurrence of behavioral and physiological changes in the foxes. Some of these genetic accounts have received empirical support concerning certain phenotypes; other accounts remain speculative (Trut et al., 2009). Recently, some scholars have forwarded the hypothesis that selection on a single biological substrate (neural crest cells) might account for the full array of these phenotypes (Wilkins, Wrangham, \& Tecumseh Fitch, 2014). Clearly, these studies and data are important, and the conclusions that have been drawn from these studies have merit. However, those conclusions might be incomplete, and there might be a complementary story. Here, I forward two hypotheses to provide a supplementary, psychological perspective on these associations. In brief, (a) humans' interpretation of the foxes' temperament unintentionally varied along with the foxes' appearance, and (b) humans' behavior toward the foxes also unintentionally varied along with the foxes' appearance. Through these mechanisms, the foxes' appearances influenced the researchers' selection. Psychological research on human social-cognitive inferences and research on human-canine interactions provide initial support for both hypotheses. If correct, these accounts bear on our understanding of the farm foxes, add nuance to the prevailing "shared genetic variants" account (Belyaev, 1979; Trut, 1999), and may further inform our understanding of humans' role in domestication.

The first hypothesis from psychology for why temperament and appearance covary in Belyaev's foxes involves human inferences about others based on attractiveness - the "what is beautiful is good" stereotype (Dion, Berscheid, \& Walster, 1972). More attractive human adults are assumed to be nicer, more predictable, and less threatening (Dion et al., 1972); teachers rate more attractive students as friendlier (Dion, 1972; Ritts, Patterson, \& Tubbs, 1992); they attribute less attractive students' transgressions to stable traits while attributing more attractive students' transgressions to fleeting states; and adults interpret cuter babies to be "good" and less problematic (Stephan \& Langlois, 1984). These inferences are made rapidly and unintentionally. Perceived attractiveness also influences humans' inferences about the temperaments of

\footnotetext{
${ }^{1}$ The occurrence of these morphological phenotypes differs in rate and in degree between species (Trut, 1999). And associations between morphology and temperament may differ between species - for example, horses and cats with mottled coats or light coats do not tend to possess "tamer" temperaments (e.g., Brunberg, Gille, Mikko, Lindgren, \& Keeling, 2013; Stelow, Bain, \& Kass, 2016).
} 
nonhuman animals, including canines (for a review, see Borgi \& Cirulli, 2016). Studies in which participants evaluate still images of dogs (i.e., eliminating the influence of dogs' actual behavior) have been particularly revealing in identifying links between humans' judgments of dogs' appearances and temperaments. People infer that dogs whom they judge to be cuter are also more amicable (Thorn, Howell, Brown, \& Bennett, 2015). Dogs with floppy ears (as opposed to pointed ears) and lighter coats (as opposed to black coats) are rated as more agreeable and emotionally stable (Fratkin \& Baker, 2013). In contrast, dogs with pointed (cropped) ears are perceived as more aggressive than dogs with floppy (uncropped) ears (Mills, Robbins, \& Von Keyserlingk, 2016). Thus far, controlled studies like these (in which raters are blind to the dogs' actual behavior) have not yet established whether all of these morphological phenotypes (e.g., curly tails) lead humans to infer more positive traits in canines.

It is reasonable to extrapolate these findings to researchers tasked with evaluating the foxes' temperament - there is no reason to believe that they would not be subject to these same psychological processes and biases. Based on Trut's account (Dugatkin \& Trut, 2017), in the early stages of the project she was the sole researcher coding the farm-foxes' behavior; thus, the resulting data could reflect a host of common and idiosyncratic biases (Kazdin, 1977). However, importantly, even if an additional coder had evaluated the foxes' behavior (a customary practice in contemporary behavioral work), and even if both coders had established interobserver agreement, common social-cognitive biases can still affect behavioral coding. Similar biases held by multiple (independent) coders can lead to their (independently) coding the same foxes the same way-based, in part, on the foxes' appearance. Thus, Trut and colleagues could have unintentionally interpreted more attractive foxes to be less aggressive and friendlier (and more "beastly" foxes as more aggressive), and then selected foxes based, partly, on perceived temperament. This critique is not exclusive to these researchers or to these foxes-it applies as well to studies conducted with other species in other labs that have employed similar methods to study relations among behavioral and morphological phenotypes.

Others' attractiveness influences not only the inferences that we make about them but also how we treat them. For example, human adults are inspired to provide better care to cuter infants as opposed to less attractive infants (Glocker et al., 2009), and less attractive children are punished more harshly relative to their more attractive peers (Berkowitz \& Frodi, 1979). Building upon the first hypothesis, the second hypothesis concerns how humans elicit behavior from others. Trut and colleagues might have been, unintentionally, more kind and welcoming toward the more attractive foxes. Because they were treated better, these foxes might have, in turn, behaved friendlier toward the humans; conversely, the least attractive foxes might have been treated relatively poorly and thus, in turn, behaved more aggressively. Variability in the researchers' body language could have been subtle and unintentional and could have nonetheless influenced the foxes' behavior. This hypothesis gains support from recent research demonstrating that many dogs are skilled at reading human facial expressions - for example, they can discriminate between novel happy and angry human faces even when shown just a portion of the faces (Huber, 2016; Müller, Schmitt, Barber, \& Huber, 2015). As well, dogs can detect and react to humans' subtle threatening behavioral cues - they behave more aggressively toward strangers who approach them hesitantly and silently as opposed to strangers who approach at a typical walking speed while vocalizing (Vas, Topál, Gácsi, Miklósi, \& Csányi, 2005). Thus, a reasonable hypothesis is that the less attractive farm foxes elicited more negative behaviors from Trut and colleagues; these reactions were detected by the foxes, which behaved more aggressively in turn. Thus, researchers potentially selected foxes based, partly, on variability in their elicitation of behavior from the foxes. While research with dogs (cited above) lends initial support to this elicitation hypothesis for the domestication of dogs, additional data are necessary to test whether these processes could also take place in the domestication of the farm foxes and other animals.

It is unlikely that attractiveness would compensate for extremely aggressive behavior - even adorable foxes would have been removed from the breeding population were they to attack a researcher. It is also unlikely that attractiveness played a large role in the selection process within the first several generations of foxes, when most foxes behaved aggressively toward the researchers (Belyaev, 1979). Rather, after several generations, when tameness became more common in the population, the most attractive of the farm foxes might have been interpreted to be especially nonaggressive and "dog-like" in behavior. Selection for tameness likely also resulted in foxes that were more sensitive to nuances in the researchers' behavioral reactions, discussed earlier. This would be consistent with observations that changes in the animals' morphology began to appear several generations after changes in their temperament (Trut, 1999). What would remain in the researchers' breeding pool were extremely tame foxes as well as relatively tame but very attractive foxes that were perceived to be less aggressive and/or that displayed less aggression because they were (unintentionally) treated more kindly by the researchers. If this pool bred and researchers continually removed foxes that were deemed to be more aggressive (because of their actual aggressive behavior and, inadvertently, their attractiveness), then over generations the pool would become more densely populated with foxes that were both less aggressive and more attractive. An implication of this hypothesized process is that the covariation of the 
foxes' attractiveness and tameness is partly an artifact of human psychological processes - social inferences and the behaviors that stem from those inferences - at play in the selection process.

Importantly, I do not intend to dismiss the seminal work conducted by Belyaev, Trut, and colleagues. Nor do I intend to dismiss the plethora of other work conducted over the past several decades that collectively points to the likelihood of shared genetic variants for certain aspects of animals' appearances and behaviors (e.g., Albert et al., 2009; Wilkins et al., 2014). I aim only to highlight that there are additional psychological variables that must be considered when accounting for mechanisms behind the correlation of these phenotypes in domesticated animals.

Although it is feasible that the processes I have outlined took place in the farm-fox study and played some role, more generally, in the domestication of other species, these hypotheses must be directly tested. One way to test these hypotheses is to limit how much human social inferences and behaviors can affect animal selection; a methodological obstacle that is now more navigable with new technologies. For example, researchers could sample farm foxes and record their behavior while they are approached and handled by a person wearing translucent glasses that substantially distort their view of the canines' features. During these interactions, motion-capture technology (e.g., Xsens; see Abson \& Palmer, 2015) could record the foxes' posture and movement; audio recordings could capture vocalizations. Critically, the motion-capture technology would not record the foxes' other physical phenotypes (e.g., features of their coat, face, ears, tail). A second (comparison) group of foxes would be approached and handled by researchers with unobstructed vision, and those foxes' behaviors would be recorded using traditional video recordings. Independent coders, unaware of the study's hypotheses, would evaluate the foxes' temperament based on the respective recordings, and the "tamest" foxes in both samples would remain in their respective breeding populations. This process would take place across at least 10 generations. On the hypotheses outlined here-implicating the researchers' social inferences and behaviors in the selection process- the "cuter" domestic phenotypes should eventually be more prevalent in the comparison population than in the experimental population. Of course, this is just one of many possible study designs that may be used to test these hypotheses. ${ }^{2}$

This supplementary, psychological perspective on the cooccurrence of behavioral phenotypes and morphological phenotypes can be extended beyond the famous farm foxes. If empirically supported, this perspective could contribute to accounts of the phylogeny of domestic dogs and potentially other domesticated species.

\footnotetext{
${ }^{2}$ For example, studies could be conducted with mammalian species that reach reproductive age more quickly than foxes.
}

Acknowledgements I thank Henry Wellman, Laura Novick, Drew Bailey, and Lisa Fazio for their helpful comments on earlier versions of this manuscript.

\section{References}

Abson, K., \& Palmer, I. (2015). Motion capture: Capturing interaction between human and animal. The Visual Computer, 31, 341-353. https://doi.org/10.1007/s00371-014-0929-2

Albert, F. W., Carlborg, Ö., Plyusnina, I., Besnier, F., Hedwig, D., Lautenschläger, S., ... Pääbo, S. (2009). Genetic architecture of tameness in a rat model of animal domestication. Genetics, 182, 541-554. https://doi.org/10.1534/genetics.109.102186

Arcus, D., \& Kagan, J. (1995). Temperament and craniofacial variation in the first two years. Child Development, 66, 1529-1540. https://doi. org/10.2307/1131662

Belyaev, D. K. (1979). Destabilizing selection as a factor in domestication. Journal of Heredity, 70, 301-308. https://doi.org/10.1093/ oxfordjournals.jhered.a109263

Berkowitz, L., \& Frodi, A. (1979). Reactions to child's mistakes as affected by her/his looks and speech. Social Psychology Quarterly, 42, 420-425. https://doi.org/10.2307/3033814

Borgi, M., \& Cirulli, F. (2016). Pet face: Mechanisms underlying humananimal relationships. Frontiers in Psychology, 7, 1-11. https://doi. org/10.3389/fpsyg. 2016.00298

Brunberg, E., Gille, S., Mikko, S., Lindgren, G., \& Keeling, L. J. (2013). Icelandic horses with the silver coat colour show altered behaviour in a fear reaction test. Applied Animal Behaviour Science, 146, 72 78. https://doi.org/10.1016/j.applanim.2013.04.005

Darwin, C. (1859). The origin of species. New York: Gramercy Books.

Dion, K. K. (1972). Physical attractiveness and evaluation of children's transgressions. Journal of Personality and Social Psychology, 24, 207-213. https://doi.org/10.1037/h0033372

Dion, K. K., Berscheid, E., \& Walster, E. (1972). What is beautiful is good. Journal of Personality and Social Psychology, 24, 285-290. https://doi.org/10.1037/h0033731

Dugatkin, L., \& Trut, L. N. (2017). How to tame a fox and build a dog. American Scientist, 105, 240. https://doi.org/10.1511/2017.105.4. 240

Fratkin, J. L., \& Baker, S. C. (2013). The role of coat color and ear shape on the perception of personality in dogs. Anthrozoos, 26, 125-133. https://doi.org/10.2752/175303713X13534238631632

Glocker, M. L., Langleben, D. D., Ruparel, K., Loughead, J. W., Gur, R. C., \& Sachser, N. (2009). Baby schema in infant faces induces cuteness perception and motivation for caretaking in adults. Ethology, 115, 257-263. https://doi.org/10.1111/j.1439-0310.2008. 01603.x

Hare, B. (2007). From nonhuman to human mind: What changed and why. Psychological Science, 16, 60-64. https://doi.org/10.1111/j. 1467-8721.2007.00476.x

Huber, L. (2016). How dogs perceive and understand us. Current Directions in Psychological Science, 25, 339-344. https://doi.org/ 10.1177/0963721416656329

Jensen, P., Persson, M. E., Wright, D., Johnsson, M., Sundman, A. S., \& Roth, L. S. V. (2016). The genetics of how dogs became our social allies. Current Directions in Psychological Science, 25, 334-338. https://doi.org/10.1177/0963721416657050

Kazdin, A. E. (1977). Artifact, bias, and complexity of assessment: The ABCs of reliability. Journal of Applied Behavior Analysis, 10(1), 141-150. https://doi.org/10.1901/jaba.1977.10-141

Keeler, C. E. (1947). Coat color, physique, and temperament: Materials for the synthesis of hereditary behavior trends in the lower mammals and man. The Journal of Heredity, 38, 271-277. 
Kubinyi, E., Sasvári-Székely, M., \& Miklósi, Á. (2011). "Genetics and the social behavior of the dog" revisited: Searching for genes relating to personality in dogs. In M. Inoue-Murayama, S. Kawamura, \& A. Weiss (Eds.), From genes to animal behavior (pp. 255-274). Tokyo: Springer Japan. https://doi.org/10.1007/978-4-431-538929_12

Lakatos, G., Soproni, K., Dóka, A., \& Miklósi, Á. (2009). A comparative approach to dogs' (Canis familiaris) and human infants' comprehension of various forms of pointing gestures. Animal Cognition, 12, 621-631. https://doi.org/10.1007/s10071-009-0221-4

Lane, J. D., Wellman, H. M., Olson, S. L., Miller, A. L., Wang, L., \& Tardif, T. (2013). Relations between temperament and theory of mind development in the United States and China: Biological and behavioral correlates of preschoolers' false-belief understanding. Developmental Psychology, 49, 825-836. https://doi.org/10.1037/ a0028825

Miklósi, Á., Topál, J., Hare, B., \& Tomasello, M. (2005). Is there a simple recipe for how to make friends? (multiple letters). Trends in Cognitive Sciences, 9, 463-465. https://doi.org/10.1016/j.tics.2005. 08.009

Mills, K. E., Robbins, J., \& Von Keyserlingk, M. A. G. (2016). Tail docking and ear cropping dogs: Public awareness and perceptions. PLOS ONE, 11, e0158131. https://doi.org/10.1371/journal.pone. 0158131

Müller, C. A., Schmitt, K., Barber, A. L. A., \& Huber, L. (2015). Dogs can discriminate emotional expressions of human faces. Current Biology, 25, 601-605. https://doi.org/10.1016/j.cub.2014.12.055

Pérez-Guisado, J., Lopez-Rodríguez, R., \& Muñoz-Serrano, A. (2006). Heritability of dominant-aggressive behaviour in English Cocker Spaniels. Applied Animal Behaviour Science, 100, 219-227. https://doi.org/10.1016/j.applanim.2005.11.005

Ritts, V., Patterson, M. L., \& Tubbs, M. E. (1992). Expectations, impressions, and judgments of physically attractive students: A review. Review of Educational Research, 62, 413-426. https://doi.org/10. 3102/00346543062004413

Song, J., Volling, B. L., Lane, J. D., \& Wellman, H. M. (2016). Aggression, sibling antagonism, and theory of mind during the first year of siblinghood: A developmental cascade model. Child Development, 87, 1250-1263. https://doi.org/10.1111/cdev.12530

Stelow, E. A., Bain, M. J., \& Kass, P. H. (2016). The relationship between coat color and aggressive behaviors in the domestic cat. Journal of Applied Animal Welfare Science, 19, 1-15. https://doi.org/10.1080/ 10888705.2015.1081820

Stephan, C. W., \& Langlois, J. H. (1984). Baby beautiful: Adult attributions of infant competence as a function of infant attractiveness. Child Development, 55, 576. https://doi.org/10.2307/1129969

Thorn, P., Howell, T. J., Brown, C., \& Bennett, P. C. (2015). The canine cuteness effect: Owner-perceived cuteness as a predictor of humandog relationship quality. Anthrozoos, 28, 569-585. https://doi.org/ 10.1080/08927936.2015.1069992

Trut, L. N. (1999). Early canid domestication: The farm-fox experiment. American Scientist, 87, 160. https://doi.org/10.1511/1999.2.160

Trut, L. N., Oskina, I., \& Kharlamova, A. (2009). Animal evolution during domestication: The domesticated fox as a model. BioEssays, 31, 349-360. https://doi.org/10.1002/bies.200800070

Trut, L. N., Plyusnina, I. Z., \& Oskina, I. N. (2004). An experiment on fox domestication and debatable issues of evolution of the dog. Russian Journal of Genetics, 40, 644-655. https://doi.org/10.1023/B:RUGE. 0000033312.92773.c1

Vas, J., Topál, J., Gácsi, M., Miklósi, A., \& Csányi, V. (2005). A friend or an enemy? Dogs' reaction to an unfamiliar person showing behavioural cues of threat and friendliness at different times. Applied Animal Behaviour Science, 94, 99-115. https://doi.org/10.1016/j. applanim.2005.02.001

Wellman, H. M., Lane, J. D., Labounty, J., \& Olson, S. L. (2011). Observant, nonaggressive temperament predicts theory-of-mind development. Developmental Science, 14, 319-326. https://doi.org/10. 1111/j.1467-7687.2010.00977.x

Wilkins, A. S., Wrangham, R. W., \& Tecumseh Fitch, W. (2014). The "domestication syndrome" in mammals: A unified explanation based on neural crest cell behavior and genetics. Genetics, 197, 795-808. https://doi.org/10.1534/genetics.114.165423 